\title{
DOCENCIA EN MATEMÁTICAS: VOCES LATINOAMERICANAS EN LA \\ TRANSICIÓN HACIA LA ENSEÑANZA A DISTANCIA POR COVID-19
}

\author{
TEACHING IN MATHEMATICS: LATIN AMERICAN VOICES IN THE TRANSITION TO \\ DISTANCE EDUCATION DUE TO COVID-19
}

\begin{abstract}
Francisco Javier Lezama Andalón Centro de Investigación en Ciencia Aplicada y Tecnología Avanzada-IPN. México jlezamaipn@gmail.com

Rebeca Flores García Programa Interdisciplinario para el Desarrollo Profesional Docente en Matemáticas, Cinvestav-IPN. México rebeca.flores@cinvestav.mx

Gabriela Buendía Abalos Red de Centros de Investigación en Matemática Educativa. México buendiag@hotmail.com

Elizabeth Mariscal Vallarta Dirección de Formación e Innovación Educativa-IPN. México emariscal@ipn.mx
\end{abstract}

\begin{abstract}
Resumen
Este escrito busca colocar en el espacio público la voz del profesor de matemáticas al vivir un fenómeno de transición hacia la enseñanza a distancia debido a una indicación de suspender actividades escolares presenciales, pero dando continuidad al acto educativo. Constituye una investigación que busca entender las vivencias y acciones del profesor. Se hace con una actitud empática para encontrar en las palabras mismas de sus actores el contenido, fundamento y justificación de sus actos. La información se recolectó a través de las respuestas a un cuestionario de trece preguntas respondido por profesores de Argentina, Colombia, Chile y México de nivel básico, medio superior y superior. Sus respuestas se tematizaron para dar lugar a un ejercicio en el que las vivencias de los profesores se plasmaron a manera de una diversidad de voces.
\end{abstract}

Palabras clave: COVID, educación a distancia, fenómeno de transición, profesor

Investigación e Innovación en Matemática Educativa (2020) Volumen 5

Recibido: Agosto 26, 2020. Aceptado: Noviembre 9, 2020. Publicado: Noviembre 16, 2020. 


\begin{abstract}
This paper seeks to place the voice of the mathematics teacher in a public space when experiencing a phenomenon of transition towards distance learning due to an indication to suspend classroom activities while continuing the educational act. It constitutes an investigation that seeks to understand the teacher's experiences and actions. It is done with an empathic attitude to find in the words of its actors the content, foundation and justification of their actions. The information was collected through the responses to a questionnaire of thirteen questions answered by teachers from Argentina, Colombia, Chile and Mexico of basic, upper secondary and higher educational levels. Their answers were thematized to give rise to an exercise in which the teachers' experiences were reflected in the form of a diversity of voices.
\end{abstract}

Key words: COVID, distance education, transition phenomenon, teacher

\title{
1. PRESENTACIÓN
}

Al 4 de marzo de 2020, 22 países de tres continentes diferentes habían decretado el cierre de escuelas. En México, la Secretaría de Educación Pública (SEP), en atención a la indicación de la Secretaría de Salud, publicó en el Diario Oficial de la Federación (16/03/2020) el acuerdo por el que se suspendían las clases presenciales del 23 de marzo al 17 de abril en todo el sistema escolar dependiente de la SEP. Este hecho sin precedentes fue como "medida preventiva para disminuir el impacto de propagación de la COVID-19” (DOF, 2020).

El sistema educativo enfrentó una situación en la que se detuvo la actividad escolar presencial pero no el acto educativo. Este escenario de cambio mundial fue testigo del surgimiento de un fenómeno de transición de lo presencial hacia una enseñanza a distancia.

Ubicándonos en este fenómeno de transición, hemos elegido la expresión voz del profesor para reconocer cómo lo vivieron algunos miembros del profesorado de matemáticas; le otorgamos a esa expresión una legitimidad que permite comprender experiencias e interpretaciones. Esto nos ubica en la noción de mundo de la vida de Habermas (2014) que permite establecer un sistema primario de "interpretación o imágenes del mundo, que reflejan el saber de fondo de los grupos sociales y que garantizan la coherencia en la diversidad de orientaciones de acción" (p.71).

Reconocemos el carácter dialógico de la experiencia pues vivir, de acuerdo con Bajtín (2012), es participar en un diálogo: "interrogar, oír, responder, estar de acuerdo, etc. El 
hombre participa en este diálogo todo y con toda su vida... esta palabra forma parte de la tela dialógica de la vida humana" (p. 331).

Nuestro interés era colaborar para visibilizar, metafóricamente, ese carácter dialógico de las interpretaciones que ellos mismos le daban a la experiencia. Para ello, nos posicionamos parafraseando a Roger (1964) en un enfoque centrado en la persona en el que se reconoce no sólo lo que dice la profesora o profesor, sino también sus sentimientos; escuchar la voz del otro no con un afán interpretativo sino con una actitud de respeto incondicional que permita experimentar una comprensión precisa y empática de su mundo, tal como lo ve desde su propio interior.

\section{HACIA LAS VOCES DE LOS PROFESORES}

El principal propósito que se tenía era mostrar en voz de los profesores de matemáticas cómo vivieron el momento escolar coyuntural cuando se suspendieron las clases presenciales por la emergencia sanitaria y comenzó una rápida transición para poder continuar las actividades académicas. Para ello, como investigadores en el área de la Matemática Educativa, diseñamos un cuestionario y solicitamos la cooperación voluntaria de profesores latinoamericanos de todos los niveles educativos para su llenado. Las preguntas consideraron aspectos como el tipo de institución educativa, el alcance de apoyo institucional, la forma en que llevaron la transición, lo afectivo, y las herramientas tecnológicas.

El instrumento y sus resultados pueden consultarse libremente (Lezama, 2020). En conjunto, se plantearon 10 preguntas abiertas y 3 cerradas. El cuestionario estuvo abierto durante un periodo de dos semanas, justo en medio de la etapa crítica en la que se buscaba la continuidad del acto educativo (22 de mayo al 6 de junio de 2020). Se contó con la participación de 180 profesores de matemáticas que desde una esfera privada dibujaron un espacio público o como hemos dicho, un espacio de diálogo.

Investigación e Innovación en Matemática Educativa (2020) Volumen 5 
Lo primero fue reconocer que la heterogeneidad presente debía ser respetada y promovida pues, como menciona González Ulloa Aguirre (2018), una base principal de ese espacio dialógico que queremos presentar es ser un lugar abierto a todos, del que nadie debe ser excluido. Se identificó que las características como el nivel educativo, el tipo de institución educativa o el país donde se ubicaba el profesor no delimitaban circunstancias especiales; estas diferencias -presentes en el dato numérico- se desdibujaron ante las realidades similares. Este hecho de alguna manera hermana cuestiones como niveles educativos o países y por momentos las hace indistinguibles; esto nos hizo renunciar formalmente a categorizaciones pues las voces son por sí mismas interpretaciones de la propia experiencia

Por ello, las categorías de análisis que se propusieron no contemplan estas divisiones, aunque esos datos sí se dejan entrever. Al plantear categorías de análisis con un enfoque integral, éstas surgen como temas o tópicos propios de un espacio de diálogo. Esos fueron las directrices de análisis: las primeras reacciones y el apoyo institucional, la evidencia de la brecha digital, el cambio en la atención a los alumnos, el papel de la familia, el saber matemático y el rol del docente.

Este escrito se plantea como un ejercicio de empatía en el que las voces de los docentes se escuchan. Nuestro reporte es un espacio que da la posibilidad de la coexistencia dialógica de múltiples voces y trayectorias.

\section{LO DE ANTES: EL ESCENARIO AL MOMENTO DE TRANSICIÓN}

Presentamos a continuación algunos datos que dibujan un marco referente tecnológico para el espacio de diálogo con los profesores.

El panorama latinoamericano respecto a qué tan preparados estaban los sistemas educativos para ofrecer soluciones digitales es diverso. La figura 1 resume algunas de las condiciones observadas por la división de Educación del Banco Interamericano de Desarrollo (BID) con base en los Sistemas de Información y Gestión Educativa (SIGED) (Alvarez, et 
al. 2020). Estas se refieren (renglones de la figura 1) a la situación en varios países latinoamericanos respecto a la conectividad en escuelas, al uso de plataformas digitales, la tutoría virtual, el empleo de paquetería y la existencia de repositorios para contenidos digitales previo al cierre de las escuelas:

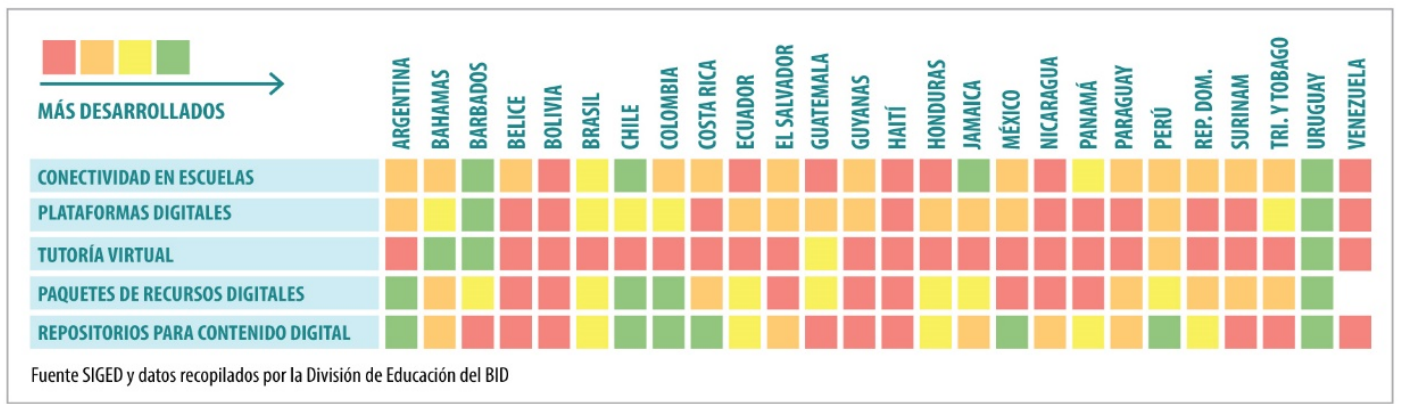

Figura 1. Condiciones digitales en países latinoamericanos

En México, el Instituto Nacional de Estadística y Geografía (INEGI) precisa que se cuenta con 80.6 millones de usuarios de internet y 86.5 millones de usuarios de telefonía celular; el 76.6 \% de la población urbana usa internet mientras que sólo el $47.7 \%$ de la rural lo usa. La figura 2 muestra el incremento del 2018 al 2019 en el empleo de celulares inteligentes, computadoras portátiles y de escritorio, televisiones con servicios de cable y abierta, así como tabletas y videojuegos. Esta información se dio a conocer un mes antes de la suspensión de clases.

En el entorno del aula, Arrieta y Montes (2011) enfatizan que aun cuando gran parte de los profesores estén conscientes de la relevancia que cobran las TICs, estas no son incluidas en sus actividades dentro del aula. Mientras que los estudiantes manejan redes sociales, generan contenidos en distintos medios, pertenecen a comunidades de su interés, los profesores las utilizan como un instrumento de consulta asincrónica.

Investigación e Innovación en Matemática Educativa (2020) Volumen 5 
Usuarios de Internet según equipo de conexión, 2019

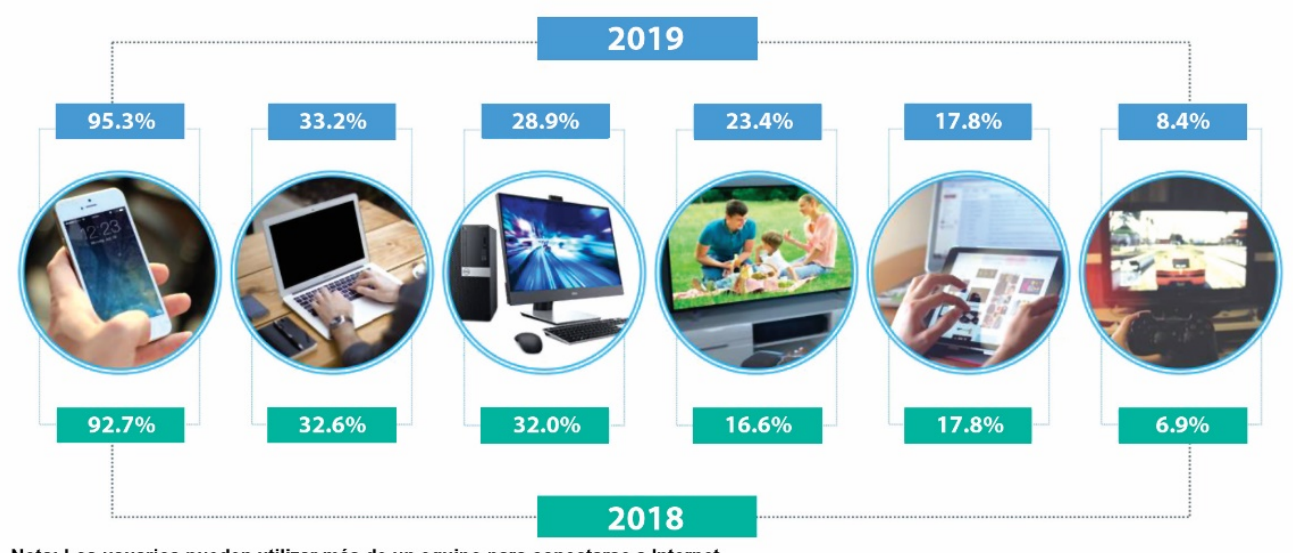

Nota: Los usuarios pueden utilizar más de un equipo para conectarse a Internet.

Figura 2. Variación de usuarios de internet según equipo de conexión (INEGI, 2019)

En este marco del panorama digital previo al cierre de las escuelas, empecemos a escuchar las voces de los profesores de nuestra exploración. Abrimos el espacio dialógico mostrando lo relativo a qué y cómo usaban dichos recursos en su aula:

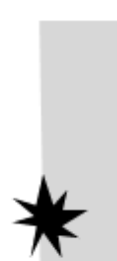

"No sé si se puede considerar como herramienta digital a las presentaciones, programas de graficación, hoja de cálculo, pero más bien presencial. A distancia, como plataformas o grupos, no tanto (era muy raro su uso)."

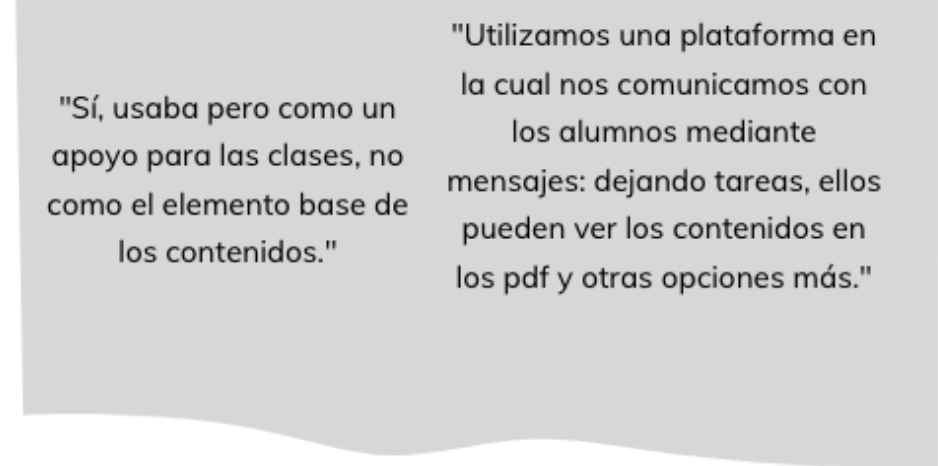

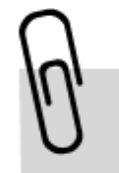

"Sí, Cabri, Geogebra, Simuladores en Física, Calculadoras de Matrices, Graficadores, etc."

"Buscaba actividades por internet que sean diferentes."

"Almacenamiento de información en la nube, comunicación y asesoría con los estudiantes mediante WhatsApp y e-mail, teletalleres en línea a través de zoom, webex meeting."

Investigación e Innovación en Matemática Educativa (2020) Volumen 5

https://doi.org/10.46618/iime.86

Red de Centros de Investigación en Matemática Educativa AC 
Se puede observar el uso de plataformas educativas, videos educativos, herramientas de mensajería y comunicación, así como software especializado en algunas aulas de profesores desde el nivel básico al superior:

Nivel superior:

sí, usaba plataforma moodle con varios de los recursos que ofrece como wikis, foros, tareas, cuestionarios, encuestas.

Medio superior:

Sí, tenemos una plataforma en el colegio para dejar trabajos y tareas y en Matemáticas usamos GeoGebra.

Básico:

Sí, utilizaba un blog, correo electrónico, softwares educativos y aplicaciones en Android

Aunque se reconoce que no siempre era posible por restricciones de las propias instituciones:

Anteriormente utilizaba herramientas digitales, sin embargo no en esta magnitud. La razón es que la institución donde trabajo actualmente está un poco en contra del uso de estas herramientas debido a que, en otras ocasiones, el mal uso de las mismas por parte de docentes y estudiantes fomentaban escándalos que eran viralizados en redes sociales.

Este escenario, con la diversidad de usos de medios digitales en esferas privadas y públicas, es donde se lleva se desarrolla el espacio dialógico de la transición.

\section{Y LLEGÓ EL MOMENTO}

Difícilmente el mundo estaba preparado para lo que fue ocurriendo con el avance de la COVID-19. En este ambiente, el profesor sabía que de alguna manera la situación le iba a afectar:

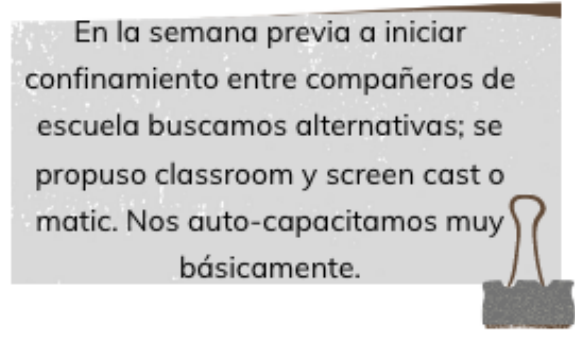

Investigación e Innovación en Matemática Educativa (2020) Volumen 5 
Empezó entonces un periodo reactivo en el que hubo momentos en los que no todo salió bien:

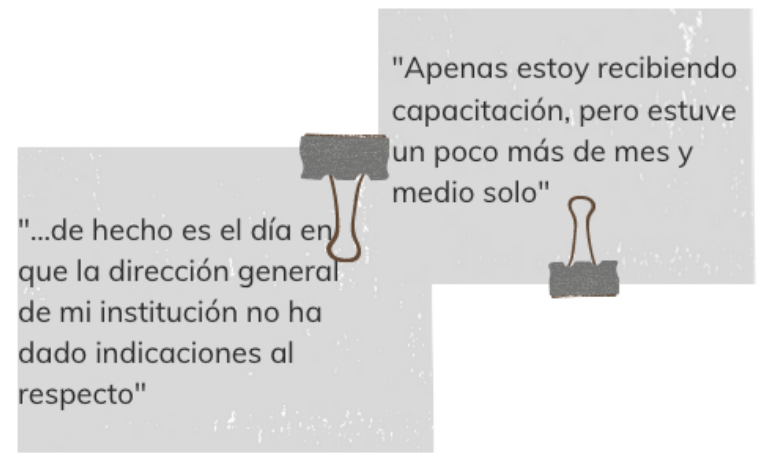

Las instituciones educativas de todo el mundo comenzaron a adoptar medidas de contingencia para garantizar que las actividades académicas pudieran mantenerse de forma remota. Por ejemplo, en México la SEP propuso recursos como libros de texto -impresos o digitales-, radio y televisión, algunos contenidos digitales en su portal, cuadernillos para zonas apartadas. Se consideró un acuerdo con Google para crear progresivamente la Suite Google (Mancera, Sera y Barrios, 2020).

La mayor parte de los profesores que participaron en la encuesta fueron notificados del cambio de formato de lo presencial a la educación remota, por autoridades educativas o gubernamentales. Algunos de ellos también afirmaron que recibieron apoyo o asesoría por parte de sus instituciones educativas.

Sin embargo, y eso es importante resaltar, hay otras voces que dan evidencia acerca de que la respuesta del profesor fue más rápida y holística que la indicación institucional. Sin esperar, los profesores buscaron y optaron por opciones que no detuviesen su actividad docente:

Investigación e Innovación en Matemática Educativa (2020) Volumen 5 


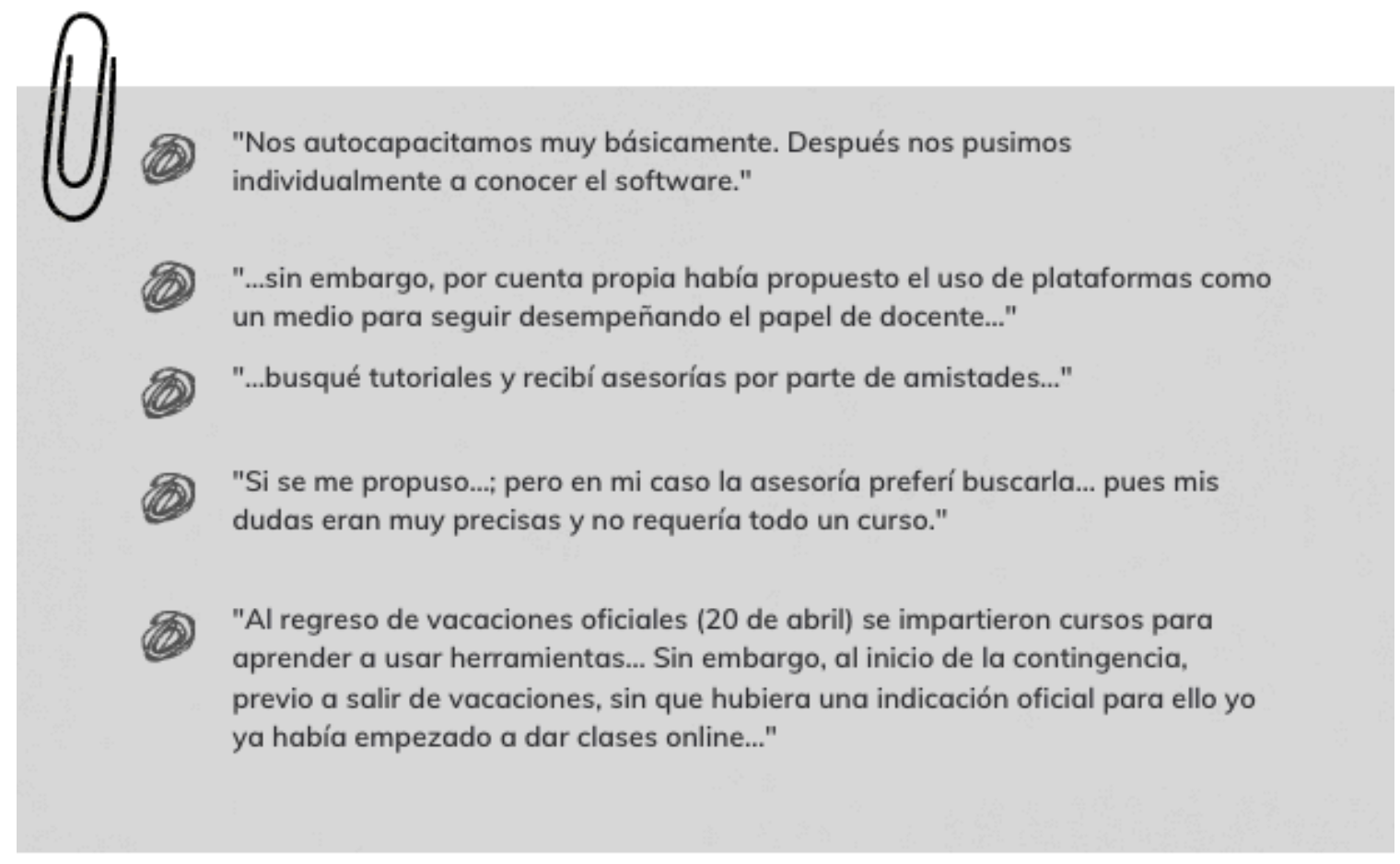

Estas respuestas advierten de las complejidades ante la necesidad inmediata de pasar de lo presencial a la distancia en medios digitales.

\section{BRECHAS DIGITALES, EN PLURAL}

La brecha digital hace referencia a la desigualdad entre las personas que pueden tener acceso o conocimiento en relación con las nuevas tecnologías y las que no. Autores como Lloyd (2020) señalan que en esta pandemia las desigualdades tienen consecuencias particularmente nocivas y de largo alcance, sobre todo por su incidencia en el sistema educativo.

Las desigualdades pueden ser en varios sentidos, lo cual provoca que se pueda hablar de al menos dos brechas digitales: en el acceso y en la utilización de los medios digitales. 


\subsection{La primera brecha digital: no hay internet, mal internet...}

Este primer nivel considera las desigualdades que se producen en el acceso a equipamiento el cual puede incluir el acceso mismo al internet. Los profesores confirman contar con internet en su casa, aunque un gran número de ellos menciona deficiencias respecto a la velocidad de conectividad o mala conectividad.

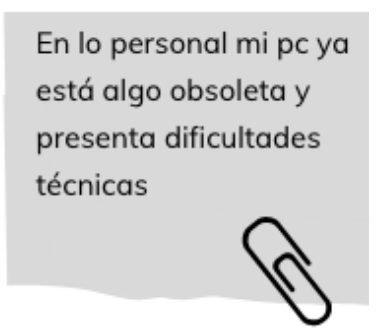

Las voces en este espacio de diálogo señalan que la preocupación central fue cómo esta primera brecha impacta en los estudiantes:

Es importante mencionar que un problema adicional es que la comunidad de donde son los estudiantes. los que se conectaban era un $60 \%$ por computadora y $40 \%$ celular pero en ambos casos la conexión era deficiente con ciertos cortes entre sesión.

\section{.}

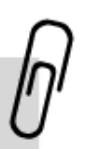


móviles; eso, previamente, no se había priorizado. La emergencia sanitaria las visibilizó cuando las aulas se trasladaron a los hogares tanto de profesores como estudiantes, quienes además podían tener padres realizando "home office".

Se evidencia en este espacio de diálogo la preocupación de los profesores por sus estudiantes, por las dificultades que enfrentarán para conectarse, por cómo y qué harán con aquella población que no tiene acceso a internet.

\subsection{Segunda brecha digital: ponernos a aprender}

Una segunda brecha diferente se hace evidente y se refiere a las desigualdades que surgen en la utilización y la comprensión de las herramientas que ya se encuentran a nuestro alcance. Esto es, aún teniendo buen internet y acceso a herramientas digitales, no se conoce su uso o no se reconoce más allá de una red social:

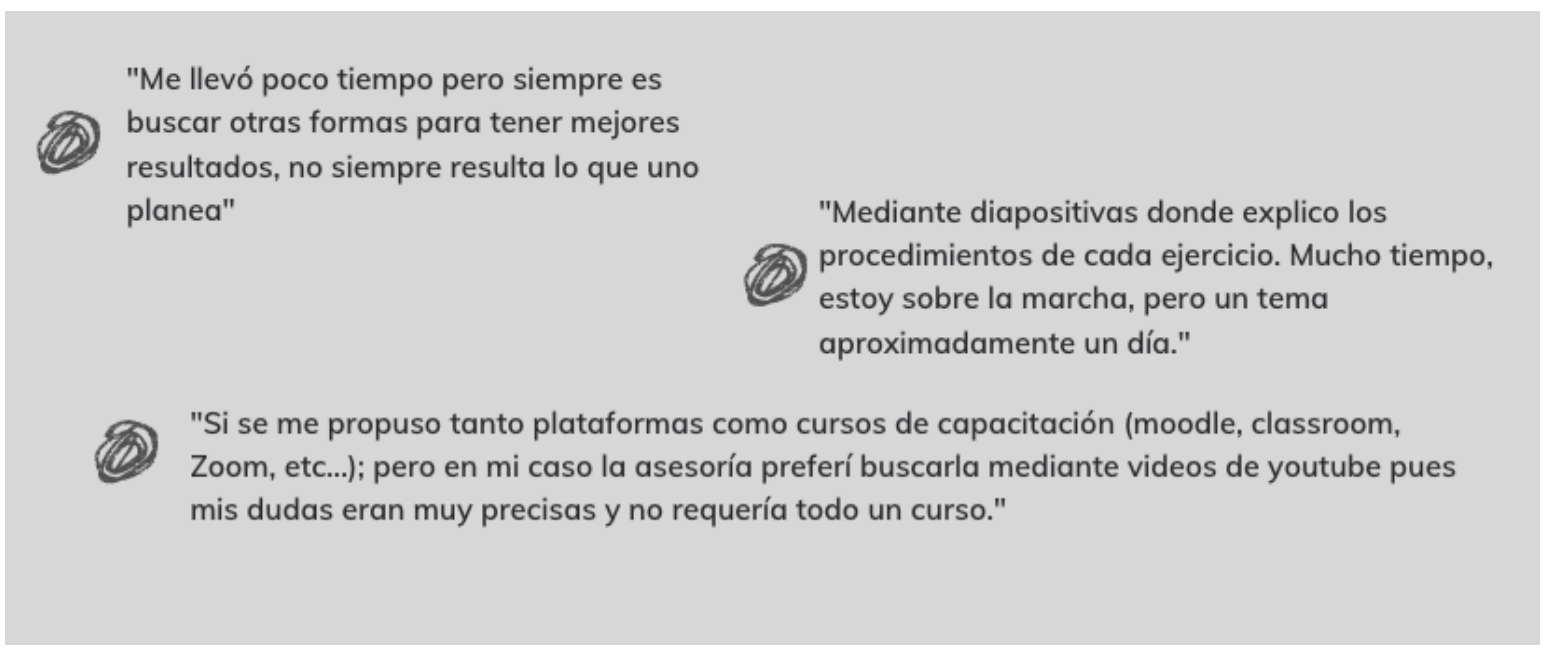

Emerge como necesidad prioritaria para el profesor familiarizarse con las herramientas para desarrollar sus clases en la modalidad virtual. La segunda brecha conllevó cambios en la práctica docente: un autoaprendizaje que considere diferentes formas de enseñanza y herramientas digitales para continuar en un entorno tan distinto a las aulas físicas.

Investigación e Innovación en Matemática Educativa (2020) Volumen 5 


\section{ALUMNOS: DESDE SU DESAPARICIÓN HASTA LA COMPLEJIDAD DE SU ATENCIÓN}

De las 180 respuestas recibidas, sólo 27 profesores consideraron que el $100 \%$ de sus estudiantes se mantuvo activo al transitar en la modalidad de atención. En cambio, 40 profesores manifestaron que sólo alrededor del 25\% de sus estudiantes participaron activamente en la nueva modalidad.

En esta pérdida de estudiantes confluyen varios factores como el no tener acceso al internet por factores económicos o culturales, primer nivel en la brecha digital. Pero también puede reconocerse que, al adecuar la presencialidad a la educación a distancia, el trabajo de aula se trató de dibujar con características iguales o similares y se incrementó de manera notable:

"Fue muy complicado, la carga de trabajo se triplicó y el cuidado que tengo que tener al diseñar las actividades es mucho mayor que si fuera presencial porque tengo que considerar las posibles dudas para aclararlas de antemano. Al principio me sentí ahogada en pendientes, hubo días que trabajé más de 10 horas y no lograba terminar. Ahora ya sistematicé algunos procesos, por ejemplo creé en mi correo una carpeta para cada uno de mis 140 alumnos y les asigné la regla de que directo se almacenen sus tareas en la carpeta, por lo que ya no veo los 300 correos por leer en mi bandeja de entrada."

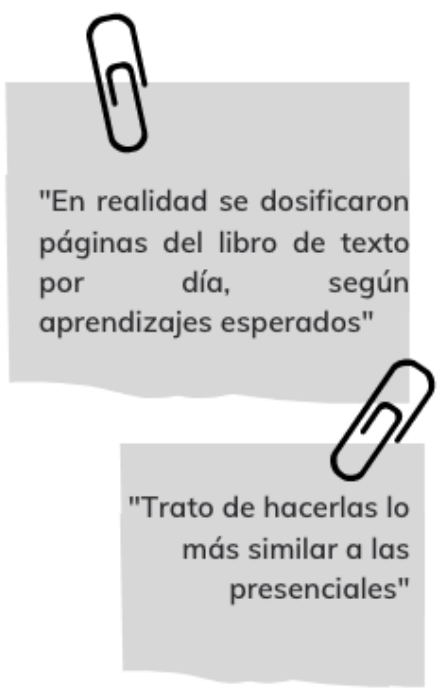

Investigación e Innovación en Matemática Educativa (2020) Volumen 5

https://doi.org/10.46618/iime.86

Red de Centros de Investigación en Matemática Educativa AC 
En ello, se pierde necesariamente la atención que se le puede brindar a un conjunto de estudiantes o bien, se duda de qué está pasando realmente:

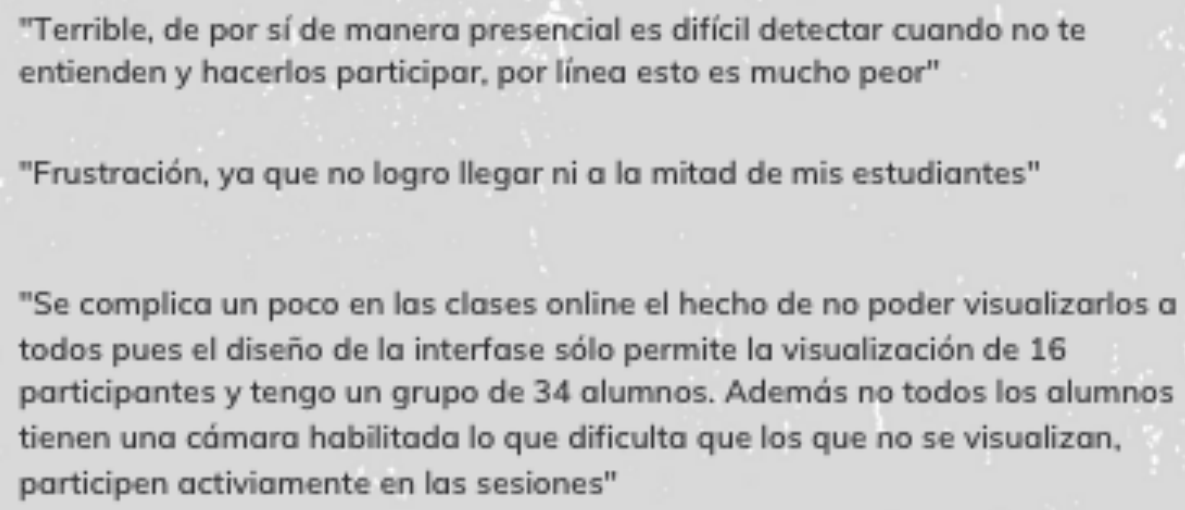

Estas respuestas dan cuenta de las distintas adversidades que enfrentaron, tales como el tiempo destinado a la preparación de la clase, las reuniones sincrónicas, la revisión de las actividades, entre otros. Cuestionamientos desde la academia y la investigación como el número adecuado de alumnos para asegurar la eficiencia y eficacia de la educación a distancia confrontan la realidad y se volvieron un reto. El titular de la SEP en México, en reconocimiento a los profesores, aseguró que, pese a la contingencia, $80 \%$ de los maestros y estudiantes de educación básica se mantuvo comunicado, lo que significa que un $20 \%$ de la población estudiantil de ese nivel se perdió (SEP, 2020).

Muchos estudiantes quedaron fuera, lo cual sin duda es una carga emocional para el profesor:

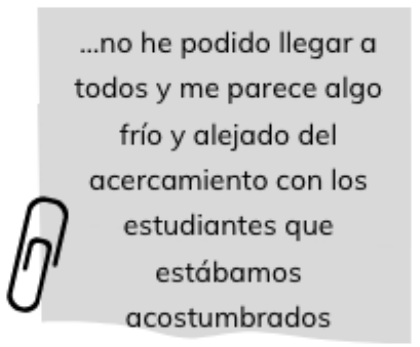

Investigación e Innovación en Matemática Educativa (2020) Volumen 5

https://doi.org/10.46618/iime.86

Red de Centros de Investigación en Matemática Educativa AC 
Este mismo panorama está en todas latitudes: la Organización de las Naciones Unidas para la Educación, la Ciencia y la Cultura (UNESCO, 2020) advierte un incremento en los índices de abandono escolar ante el impacto del COVID-19.

\section{7. ¿DANDO CLASE A TODA LA FAMILIA? EL PROFESOR Y LA FAMILIA DEL ALUMNO}

El Fondo de las Naciones Unidas para la Infancia (UNICEF) realizó recomendaciones para la educación a distancia en tiempos de COVID-19: cuidar la salud emocional de los hijos e hijas, establecer una rutina, no tratar de convertirse en el maestro o la maestra además de regular el tiempo (UNICEF, 2020). Y es que la escuela entró a casa.

Especialmente en el nivel básico, donde los estudiantes no pueden desarrollar las actividades por sus propios medios, la participación de los padres de familia repercute en el desarrollo de las actividades. Los padres de familia ocuparon un papel fundamental al ser el intermediario entre el profesor y el estudiante. Y los profesores lo hicieron notar:

"Tuve que descargar los materiales que enviaban de la secretaria en formatos pdf y descargar los videos y material de apoyos para pasarlos por WA a los padres ya que no todos cuentan con internet en casa y solo pueden comprar fichas de 30 minutos lo cual lo ocupan para descargar todo el material que les envío y de ahí vuelve a contratar ficha el fin de semana para enviarme sus evidencias"

"Por parte de la supervisión se dio la indicación de mantener contacto con los padres de familia (dependiendo sus posibilidades)"

"Me apoyo en las clases por tv y con ayuda de redes sociales para estar en contacto con padres de familia con respecto a actividades complementarias"

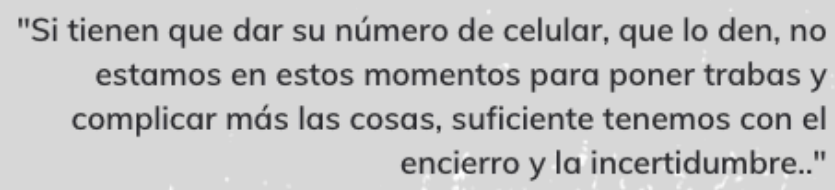

Investigación e Innovación en Matemática Educativa (2020) Volumen 5 
Se evidencia la relevancia que tiene el estar en comunicación con sus estudiantes, optando por el medio inmediato, los padres de familia. Las voces que escuchamos de los profesores señalan que la relación profesor-familia tiene ahora nuevos matices e implicaciones. Enfatizamos dos:

a) Se requirieron estrategias de comunicación diferentes en un lenguaje apropiado para que el padre o la madre acompañase al hijo o hija en el desarrollo de las actividades:

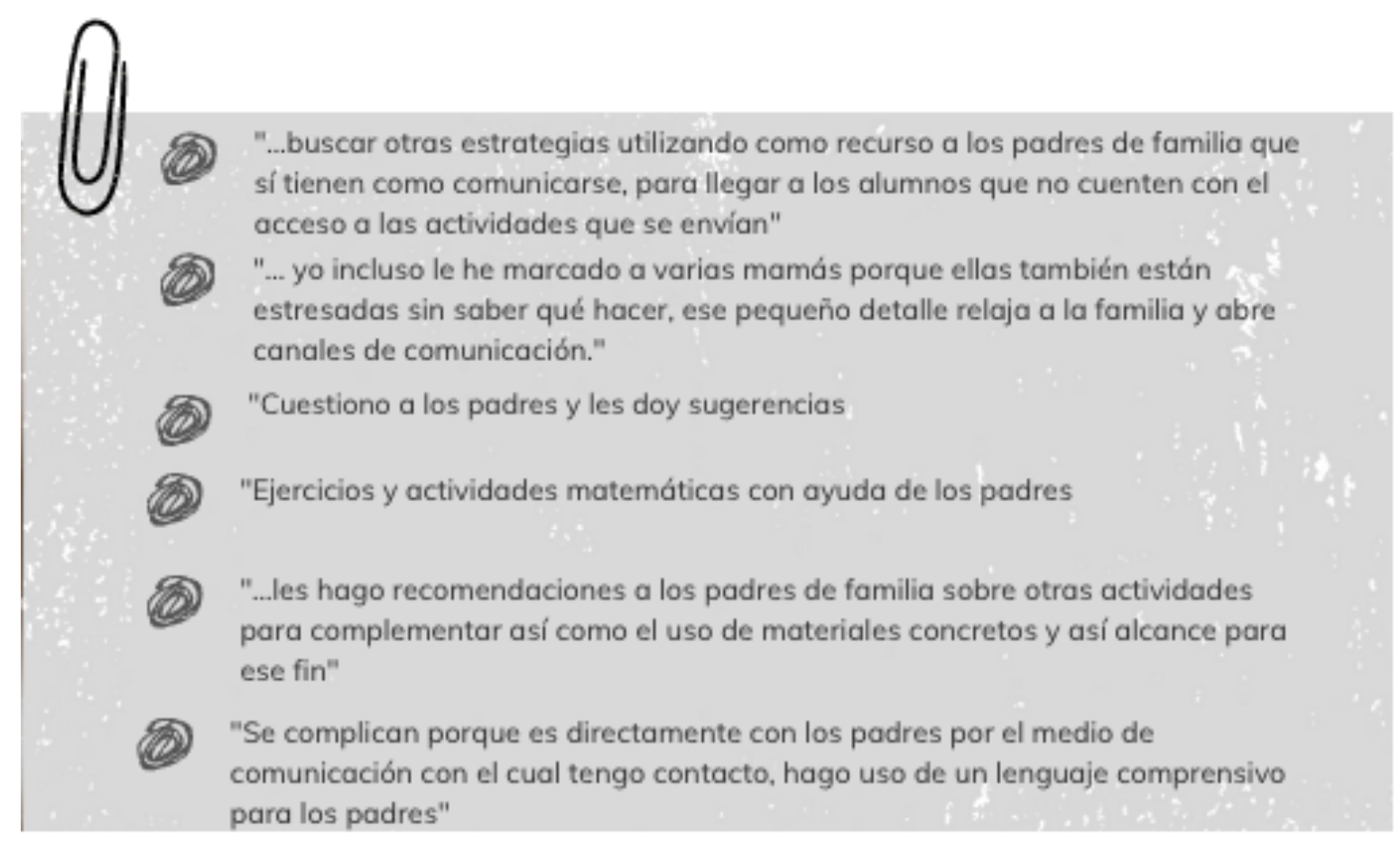

b) Se solicitaron tareas a los padres no sólo académicas, sino otras referidas a las normas de clase:

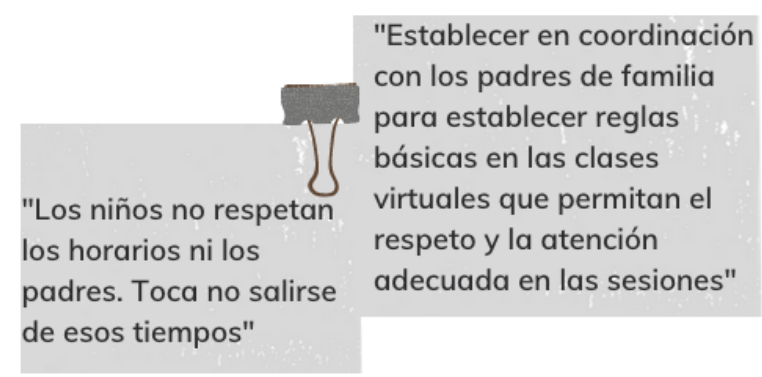

Investigación e Innovación en Matemática Educativa (2020) Volumen 5

https://doi.org/10.46618/iime.86

Red de Centros de Investigación en Matemática Educativa AC 


\subsection{Nueva comunicación con los padres}

Si bien los padres pueden ser el medio de comunicación entre los profesores y los estudiantes, se reconoce que no son el reemplazo de los profesores y, en ciertos casos, su presencia puede complejizar el acto educativo:

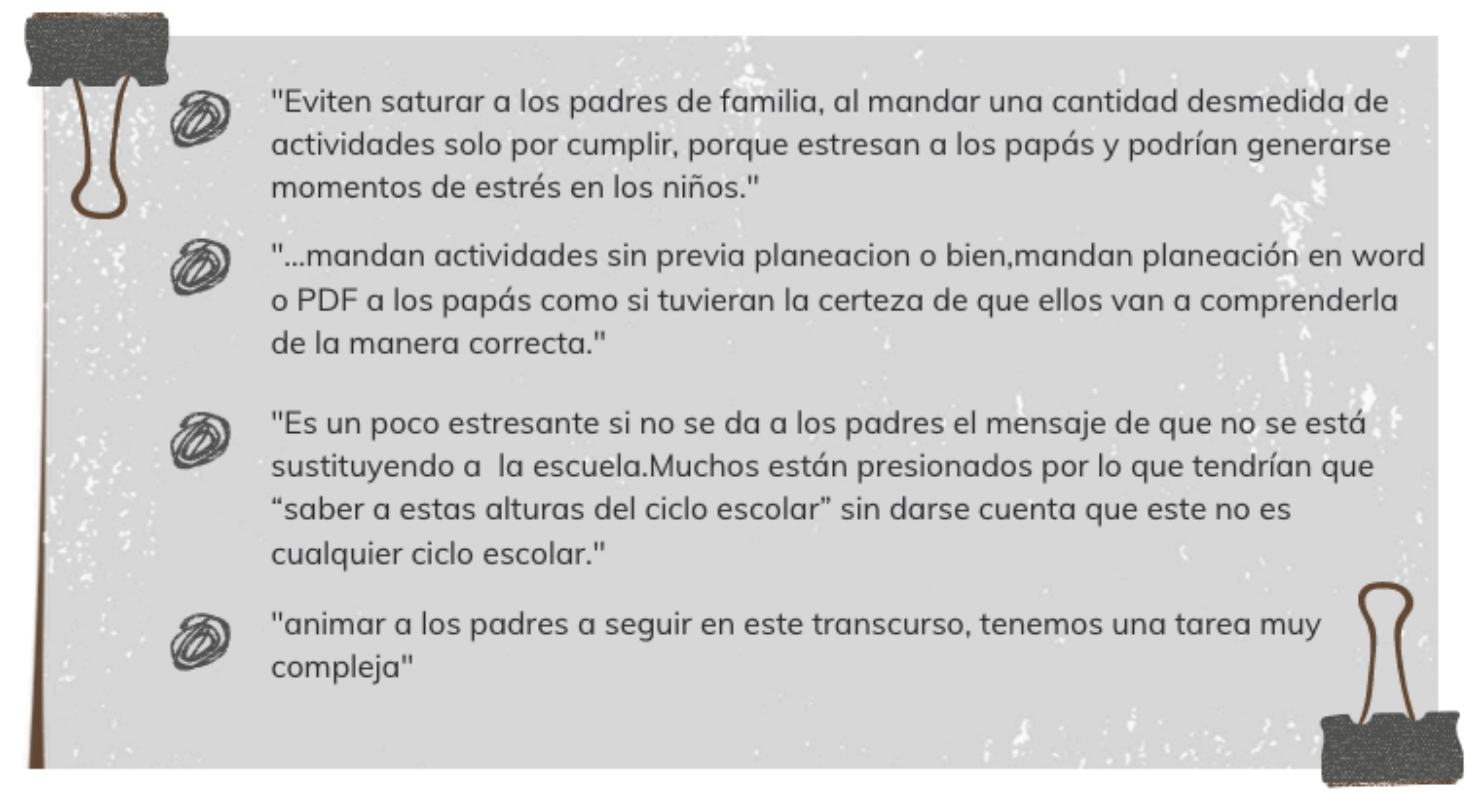

Se coincide pues en cuidar el envío de las actividades a los padres, ya que por un lado podían llegar a estresarse por la cantidad y por otro no podrían atender dudas puntuales de cada actividad y cada materia. La reflexión del profesor clama su imposibilidad de ayudar a sus estudiantes si no se cuenta con la disposición de los padres:

Investigación e Innovación en Matemática Educativa (2020) Volumen 5

https://doi.org/10.46618/iime.86

Red de Centros de Investigación en Matemática Educativa AC 


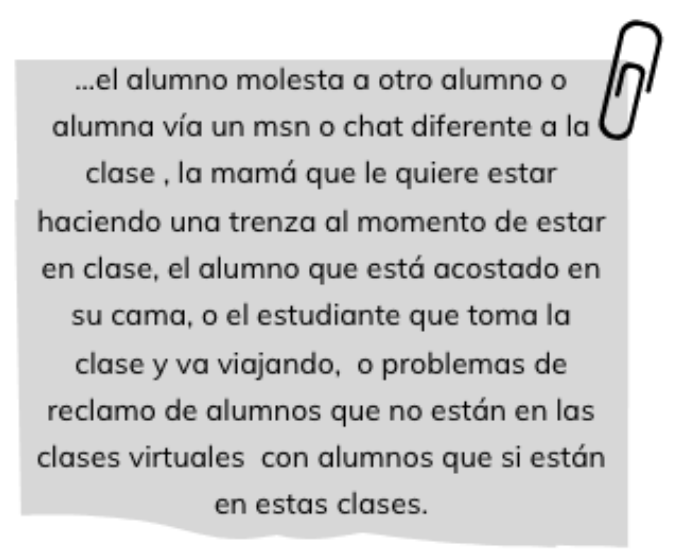

Las voces conjuntan aspectos como las dificultades para acceder a internet y el sentido de responsabilidad en el desarrollo de las clases en la modalidad virtual.
De impotencia por no poder hacer más por aquellos que no tienen acceso a internet o bien los padres dicen no tener tiempo para hacer las

Tediosas al trabajar tanto con padres como alumnos ya que al ser adolescentes muchos no hacen uso de la tecnología de forma eficaz en cuestiones académicas, y es el padre de familia quien escribe, y recibe las retroalimentaciones. actividades

\section{8. ¿Y LA MATEMÁTICA?}

Las respuestas de los profesores denotan que la transición de la modalidad presencial a la educación a distancia no provoca en ellos un conflicto disciplinar. Este cambio no complejiza el tratamiento del contenido matemático en sí, sino su comunicación:

...que no se está preparado para este tipo de actividades, por el simple hecho de ser clase presencial es lo que los estudiantes prefieren, y la adaptación a la misma es complicado para ellos, siento que no es provechoso, sobre todo para las clases de matemáticas, en donde los estudiantes se les presentan dudas y no todos tienen las facilidades para conectarse a una clase o cuenta con los recursos suficientes para llevar a cabo una clase virtual.

Las disrupciones y complicaciones parecen radicar en la manera de plasmar los objetos matemáticos; antes en la pizarra, ahora en lo digital:

Investigación e Innovación en Matemática Educativa (2020) Volumen 5

https://doi.org/10.46618/iime.86

Red de Centros de Investigación en Matemática Educativa AC 
Mando la actividad por classroom y luego cito a los alumnos a compartir dudas por Google meet. Pero es muy dificil por el poco tiempo que te da la aplicación y no poder usar un pizarrón

En pocos casos, la alusión a la matemática es explícita. Las respuestas de los profesores están orientadas a la identificación de los requerimientos básicos que la modalidad virtual demanda y a la importancia de reorganizar tanto los tiempos destinados a las clases como la selección de contenidos a desarrollar. Se reconoce en expresiones tales como:

Reduje de manera considerable el material, diseñé problemas más directos...

El contenido se adecuó de acuerdo con lo expuesto en el plan de asignatura...

Seleccioné los temas que consideré de mayor relevancia

Cambiando orden en dosificación de contenidos para abordar temas accesibles en el libro de texto

Elaboré teóricos comprimidos, adecué las tareas al formato digital, enlentecí los tiempos...

Fue necesario revisar el contenido de cada asignatura, analizar a mis estudiantes...

Algunas voces se refieren a la necesidad de plasmar el contenido matemático en formato digital y luego tener una estrategia para comunicar ese contenido:

...más tiempo de la planeación tradicional, debido a la digitalización y adecuación de la información"

Se proponen ejercicios y problemas en una guía formato pdf que se les envía por whatsapp. Luego se presentan ejemplos por medio de fotos con secuencias de resolución y se les pide trabajar con sus respectivas guias.

O bien, dejan entrever cómo van más allá ya que en sus nuevos diseños insertan actividades generadoras de aprendizajes:

...mandar video explicando actividades a los niños...

A través de un video explico qué van a realizar en la actividad

Les dejo una situación problémica luego observo y retroalimentamos

Investigación e Innovación en Matemática Educativa (2020) Volumen 5 
Hemos jugado al restaurante en casa (tapas en lugar de monedas) el supermercado (haciendo tickets de las compras) cuánto mide cada miembro de la familia, con su pie marcado en una hoja (con gráficas de los resultados) conteo de manzanas (actividades digitales en formato presentaciones) escribe tu receta (número de ingredientes y pasos)

A partir de un documento en común diseñado con actividades entre todos los profesores, utilizo los espacios del aula virtual que permite alojar material audiovisual y de texto, para proponer actividades interactivas alojadas en el banco de recursos de Geogebra...

En esta transición, no fue suficiente saber qué contenidos desarrollar, sino cómo hacerlo. Ello implicó identificar una diversidad de herramientas que permitieran poner en juego el proceso de enseñanza y aprendizaje mediante recursos tecnológicos que van desde lo más elemental, como usar un correo, trabajar en una plataforma para subir actividades hasta diseñar actividades en software especializado. Esta búsqueda por parte de los profesores para resolver los problemas técnicos de digitalización y comunicación de la matemática en el medio virtual constituyó un acercamiento masivo al uso de la tecnología para el proceso de aprendizaje de las matemáticas en la escuela.

\section{CONFRONTANDO EL NUEVO ROL DOCENTE}

Viñals y Cuenca (2016) señalan que "los denominadores más comunes que se atribuyen al nuevo rol del docente de la era 2.0 son: organizador, guía, generador, acompañante, coacher, gestor del aprendizaje, orientador, facilitador, tutor, dinamizador o asesor” (p. 110). Estas características permiten evidenciar que el docente tuvo que enfrentar un cambio en varios sentidos. Y no necesariamente fue un cambio agradable ni fácil:

Investigación e Innovación en Matemática Educativa (2020) Volumen 5 

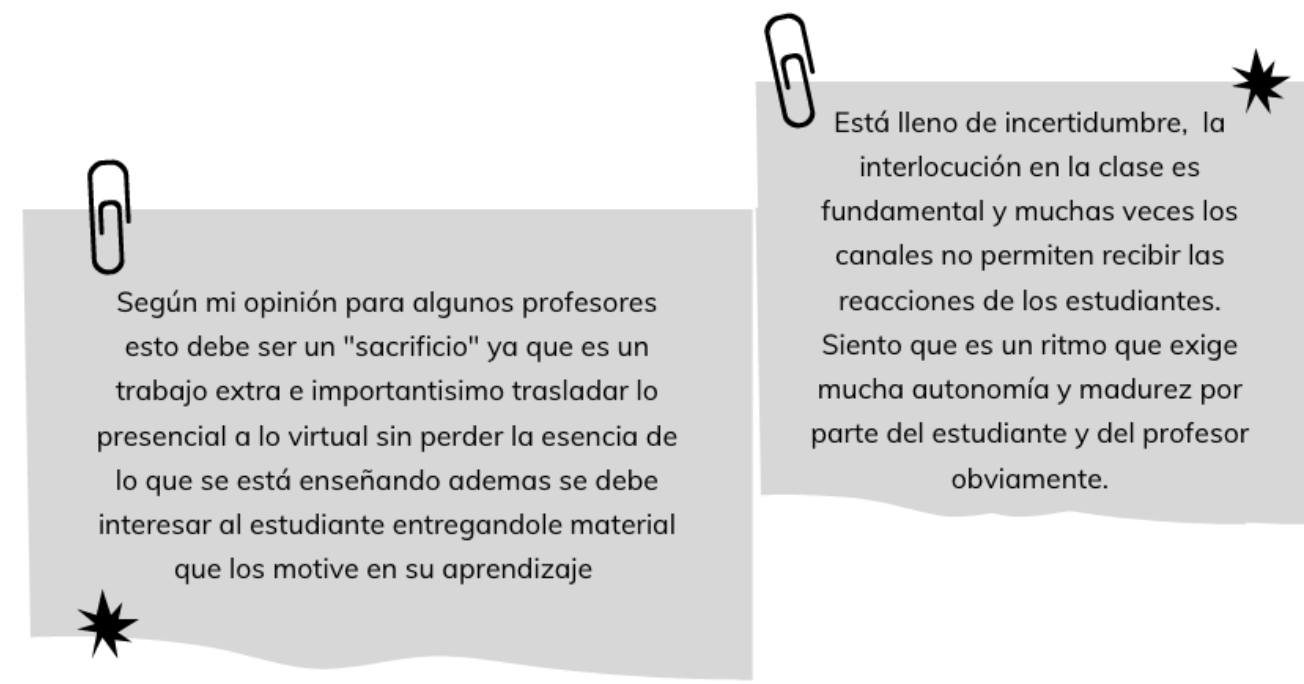

Varios elementos propios del rol docente entran en juego en las voces: se revaloriza la presencialidad, se consumen y producen nuevos medios tecnológicos, hay una necesidad de redistribuir los tiempos tanto para el diseño de las actividades como para la retroalimentación. Los profesores en sus respuestas dejan ver cómo experimentaron la distancia entre el tiempo de su propio aprendizaje y el tiempo institucional que se dispone para todo lo que implica el proceso enseñanza y aprendizaje:
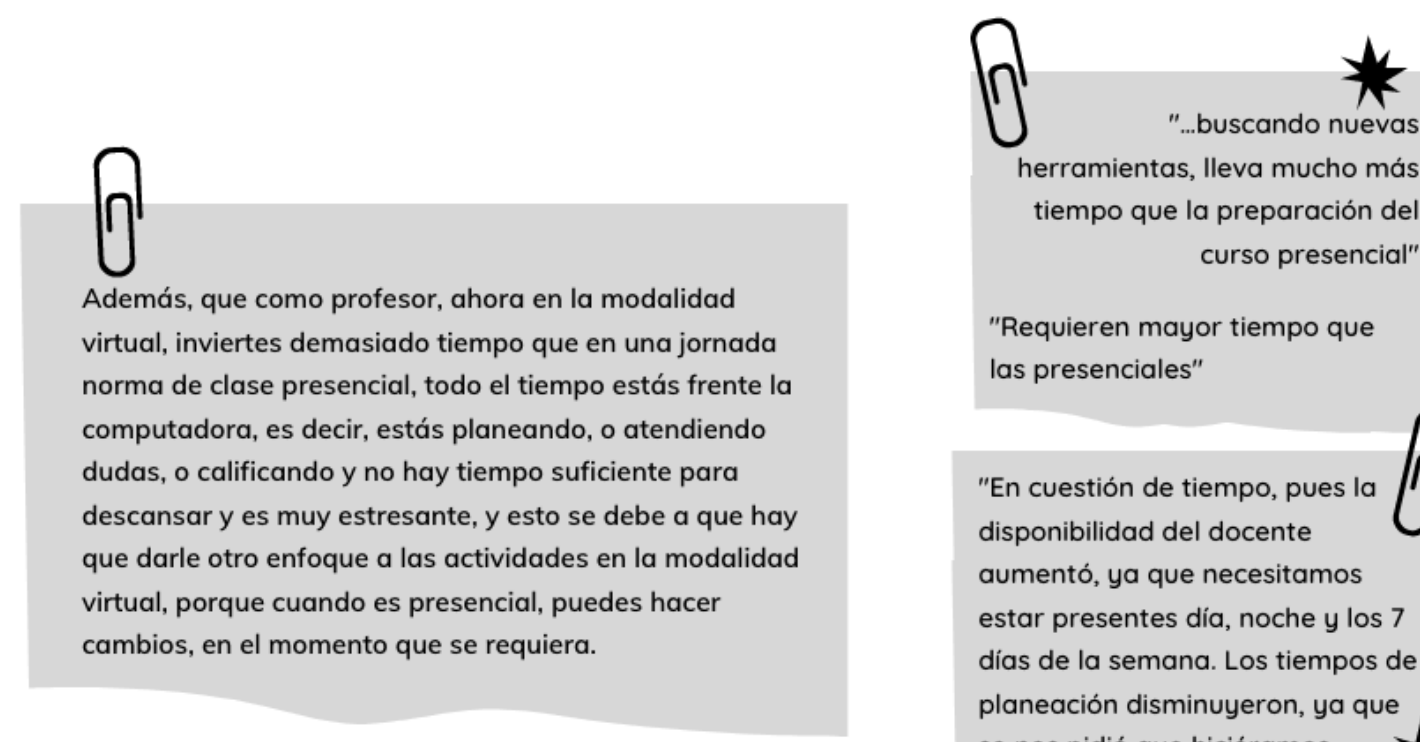

Investigación e Innovación en Matemática Educativa (2020) Volumen 5

https://doi.org/10.46618/iime.86

Red de Centros de Investigación en Matemática Educativa AC 
Las redes sociales se configuraron como fuentes primarias para mantener una comunicación real y efectiva con sus alumnos:

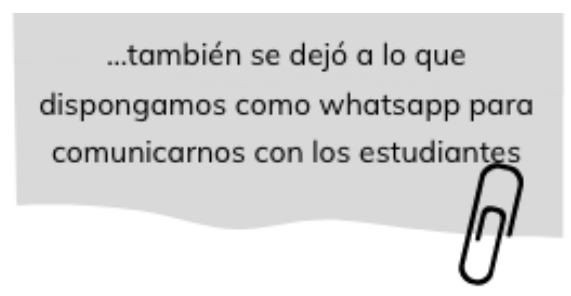

Los medios y aplicaciones digitales para usos comunes se combinaron:

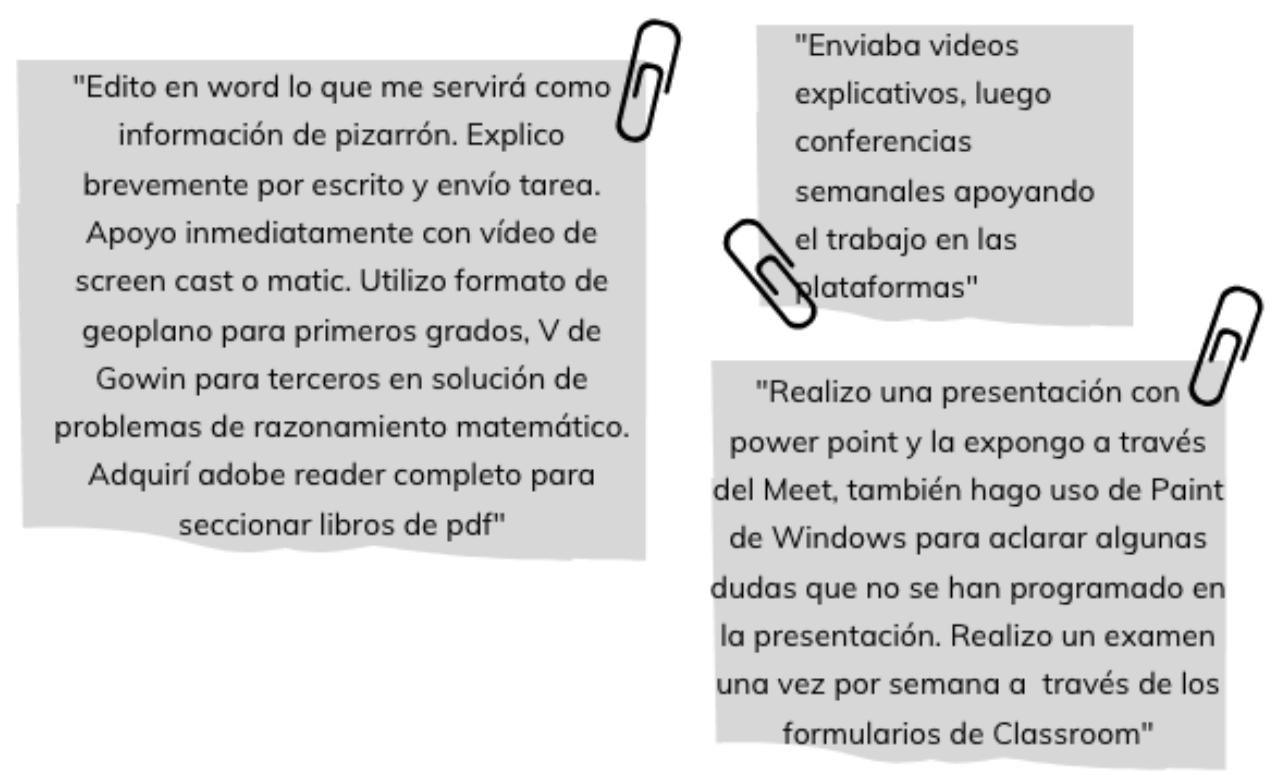

La inserción de las redes sociales en la educación fue un parteaguas. En este momento de transición fueron bienvenidas como medio de comunicación mientras que en la modalidad presencial representaban una dificultad para los profesores. Es un caos educativo en el que hay sin duda un ejercicio de autoconocimiento y autorreflexión. El profesor se cuestiona ¿Quién soy? ¿Qué hago aquí? e incluso ¿Cómo me siento? ¿Mejor sólo o acompañado? ¿Y mi institución?

Investigación e Innovación en Matemática Educativa (2020) Volumen 5 
"... entre compañeros y amigos de la escuela. Hasta la fecha. Después recurrí a lo que había de explicaciones en youtube."

"Crear un grupo de ayuda entre colegas de los distintos niveles"
"Siento que es un ritmo que exige mucha autonomía y madurez por parte del estudiante y del profesor obviamente."

"Apenas estoy recibiendo capacitación, pero estuve un poco más de mes y medio solo.
"... nos preguntemos si realmente somos docentes de matemática o solo repetimos

lo que viene en un libro"

\subsection{La educación a distancia: la nueva realidad}

La Organización de las Naciones Unidas para la Educación, la Ciencia y la Cultura (UNESCO) en su publicación del 21 de abril, reconoce que la transición al aprendizaje en línea ha sido complicada o hasta imposible (UNESCO, 2020). Esta nueva modalidad despierta posicionamientos en el profesor, incluyendo la negatividad a aceptar la modalidad por el temor a ser expuestos:

"No me gusta en línea, tenemos la oportunidad de trabajar en una comunidad donde el trato con los alumnos es de respeto, cariño, abrazos, saludos, se nos ha hecho muy complicado no tener esa

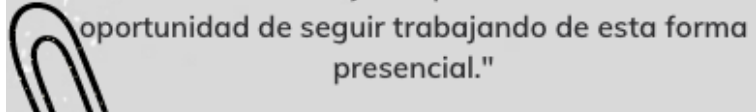

"Temor a las exposiciones abiertas. A errores o fallas que no pudiera resolver por falta del conocimiento tecnológico."

En un principio, algunos pensaban que la educación a distancia sería muy similar o parecida a las clases presenciales, más aún si no habían tenido una experiencia cercana con otra modalidad:

Investigación e Innovación en Matemática Educativa (2020) Volumen 5 


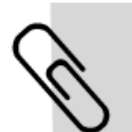

"Trato de hacerlas lo más similar a las presenciales. Trato de acercar de una manera amigable las matemáticas a los estudiantes y por supuesto, permitir que construyan, quecreen, que midan, que interactúen, etc."

Pero las propias voces reconocen que hay cosas que no funcionaron del todo bien:

"...que no sólo manden videos y links, es

"La grabación de exposiciones no creo que sea adecuada" importante transmitir en vivo para que se interactúe con los alumnos"

"Son clases muy similares a las presenciales, con explicación tradicional apoyado en presentaciones, videos y la pizarra digital. Los estudiantes preguntan en el momento que ellos quieran y se apoyan en la plataforma para reforzar $y$ entregar los trabajos."

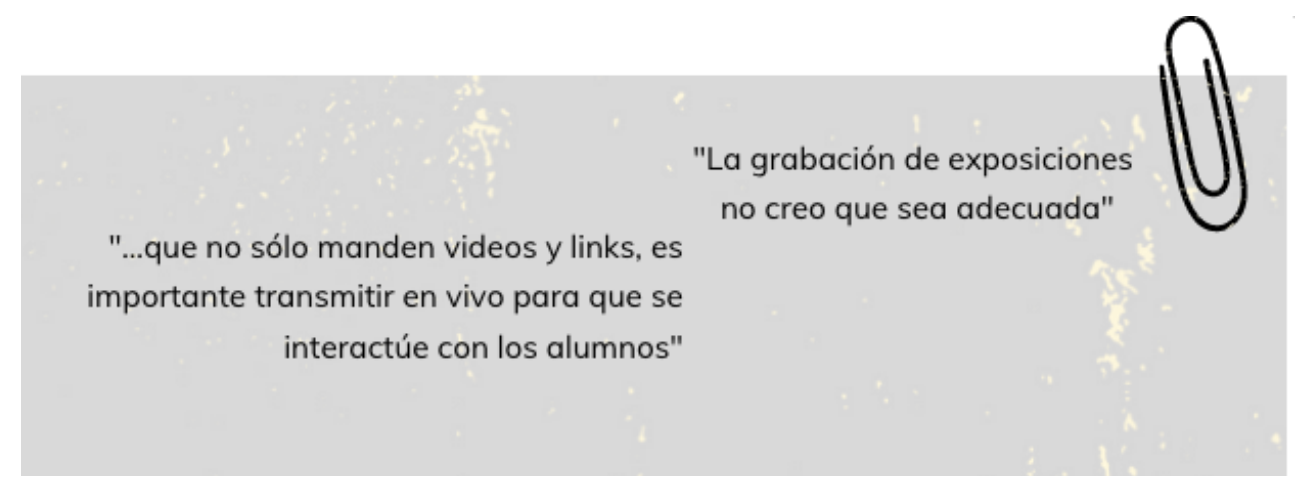

Con el paso de los días, empezaron a darse cuenta de las implicaciones tan serias que estaban enfrentando y ante lo cual tendrían que tomar decisiones para adaptarse a la educación remota.

El momento de la transición fue un momento crítico que deja marcado un antes y un después. Lo expresado por los profesores deja claro aspectos necesarios a tomar en cuenta para la reflexión permanente. Entre ellos, que la abrupta transición de modalidad se traduce en una sensación de pérdida en cuanto a la cercanía con el estudiante, de temor en el manejo de herramientas tecnológicas, pero también en la acuciosa necesidad de adquirir nuevos

Investigación e Innovación en Matemática Educativa (2020) Volumen 5 
conocimientos. Se trata de buscar soluciones inmediatas, rápidas, aun sin tener claro si serán efectivas:

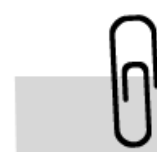

"Es un poco tedioso, algunas veces preparar una clase se lleva un poco más de tiempo debido a que, la acción en el aula se da por medio de un discurso en donde existe una mayor interacción y las ideas son expuestas en la pizarra (ideas del docente y del estudiante), sin embargo, en línea no todos los estudiantes participan y no existe un contacto directo para saber la reacción que éstos tienen. Es difícil identificar sus expresiones pues, al menos en el aula, el docente es consciente que estas reacciones dicen mucho sobre el entendimiento de un tema."

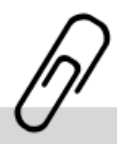

"Fue necesario revisar el contenido de cada asignatura, analizar a mis estudiantes, pues, de acuerdo a como los he conocido y de acuerdo a las evaluaciones diagnósticas, determiné un tiempo para cada una de los temas que se verían. De igual forma, el uso de tutoriales sirvió para facilitar esta transición, sin embargo, la búsqueda de los tutoriales adecuados llevó un tiempo, pues no todos los videos tienen un buen material o explican de forma oportuna."

La modalidad se reconoce y hay que cambiar. Los profesores se dan cuenta de que no se trata de un salón convencional, de que hay necesidad de experimentar y aprender y sobre todo el reconocimiento de que la modalidad va a permanecer debido a que "volver a las escuelas" no podrá ser de inmediato. En este posicionamiento se reconoce la necesidad de seguir buscando herramientas que les permitan desarrollar sus actividades y atender a sus estudiantes. Sobre todo, se trata de experimentar para decidir con qué se quedan para continuar avanzando en sus cursos:

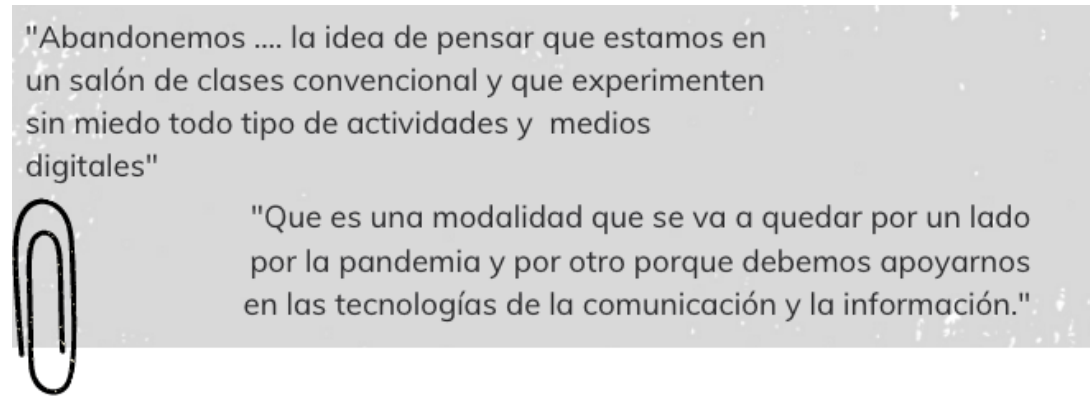

Investigación e Innovación en Matemática Educativa (2020) Volumen 5

https://doi.org/10.46618/iime.86

Red de Centros de Investigación en Matemática Educativa AC 


\section{REFLEXIÓN FINAL: UN EJERCICIO DE EMPATÍA}

Los profesores han tenido que adaptarse a nuevas formas de trabajo de forma abrupta y no planeada; se reconoce explícitamente la desigualdad en lo educativo:

Por ahora la experiencia no ha sido muy agradable en lo personal, creo que es derivado porque la pandemia nos agarró desprevenidos, y por consiguiente no hay un modelo estructural vía estos medios que permita atender tantas desigualdades y desequilibrios sociales, además no hay todavía una cultura de uso responsable de los medios por parte de los adolescentes que genera ciertas situaciones conductuales que son poco controlables por parte del docente.

En las voces se reconocen diversas sensaciones que tuvieron durante este proceso de transición.

Desde nostalgia...

Se extraña el aula y la convivencia presencial.

hasta emoción:

Además, creo que es un buen reto para profesores y estudiantes... adaptarnos a nuevas modalidades y dinámicas.

Y en ello, todo un panorama con polos opuestos e intermedios (figura 3):

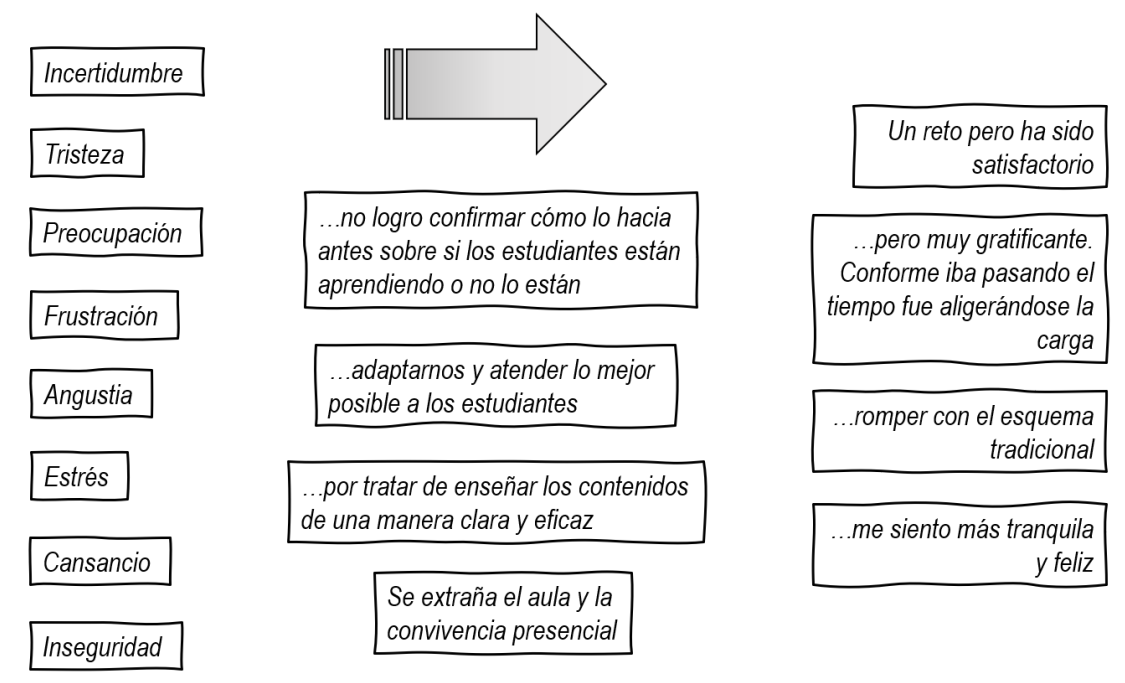

Figura 3. Las voces (elaboración propia)

Investigación e Innovación en Matemática Educativa (2020) Volumen 5

https://doi.org/10.46618/iime.86

Red de Centros de Investigación en Matemática Educativa AC 
La pandemia llegó de manera inesperada; los profesores cumplieron cabalmente. Y en ese caos, sus voces se alzan para compartir recomendaciones:

Estar preparado para abordar una enseñanza mixta

Dejarse llevar por el cambio y no intentar reproducir lo que era nuestra forma presencial en la virtualidad.

Conocer y explorar alternativas

Aprovechar los muchos medios que la tecnología nos ofrece

Experimentar

Innovar

Mantener una comunicación activa con sus alumnos

Tener en cuenta el contexto del alumno para de esta manera poder elegir la herramienta tecnológica que pueda ser de utilidad para lograr el propósito planteado.

Hacer horarios de trabajo

Hacer trabajo en colegiado

Compartir estrategias y recomendar herramientas

Estas voces dan cuenta de acciones y ajustes, pero principalmente es el sentir al transitar de una modalidad presencial a una educación remota a fin de dar continuidad a las actividades académicas en un contexto emergente. Muchos de los profesores vivieron el fenómeno en crisis al pasarlo en muy corto tiempo; se amplió su carga de trabajo para enfrentar el reto de hacerse inteligibles apoyados de un amplio espectro de herramientas digitales. En ello no olvidaron su compromiso en el aprendizaje de sus estudiantes:

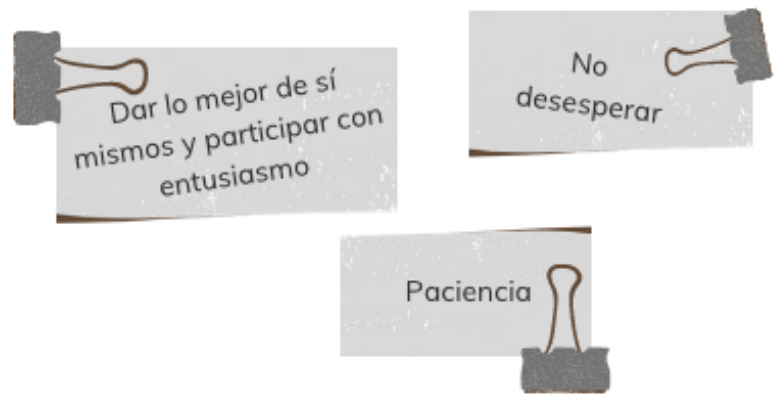

Lo mostrado es una pequeña representación de lo que los docentes de diferentes latitudes vivieron. Son voces del docente común que en un ejercicio privado nos permiten 
una reflexión pública y empática; es un espacio dialógico. Lo aprendido en el camino afectará en un futuro próximo la actividad docente en matemáticas pues hoy los profesores se encuentran repensando su práctica. El compromiso con el aprendizaje de sus alumnos es determinante para encontrar nuevas formas, metodologías y mecanismos. Estemos atentos.

\section{REFERENCIAS}

Álvarez, H., Arias, E., Bergamaschi, A., López, A. Noli, A. Ortiz, M., Pérez, M., RiebleAubourg, S. Rivera, M. Scannone, R. Vásquez, M. y Viteri, A. (2020). La educación en tiempos del coronavirus: los sistemas educativos de América Latina y el Caribe ante $\quad$ COVID Banco Interamericano de Desarrollo. http://dx.doi.org/10.18235/0002337

Arrieta, A. y Montes, D. (2011). “Alfabetización digital: El uso de las tic's más allá de una formación instrumental y una buena infraestructura", Revista Colombiana de Ciencia Animal 1 (3), 180-197.

Bajtín, M. (2012). Estética de la creación verbal. Siglo XXI Editores.

DOF (2020). Acuerdo número 02/03/20 Diario Oficial de la Federación, 16 de marzo, 2020, https://www.dof.gob.mx/nota_detalle.php?codigo=5589479\&fecha=16/03/2020

González Ulloa Aguirre, P. (2018). Espacio público y ciudadanía: ¿cómo trascender de lo privado a lo público? UNAM-Gedisa.

Habermas, J. (2014). Teoría de la acción comunicativa. Editorial Trotta.

INEGI (2019). Encuesta Nacional sobre Disponibilidad y Uso de Tecnologías de la Información en los Hogares. [Comunicado de Prensa núm. 103/20. INEGI-SCT-IFT] https://www.inegi.org.mx/contenidos/saladeprensa/boletines/2020/OtrTemEcon/EN DUTIH_2019.pdf

Lezama, J. (2020). Formulario: La voz de los y las profesoras de matemáticas en periodo de transición [Datos en bruto no publicados]. https://storage.ning.com/topology/rest/1.0/file/get/8005311689?profile=original

Lloyd, M. (2020). Desigualdades educativas y la brecha digital en tiempos de COVID-19. Educación y Pandemia. Una visión académica. (pp. 115-121). IISUE. http://www.iisue.unam.mx/investigacion/textos/educacion_pandemia.pdf 
Mancera, C. Sera, L. y Barrios, M. (2020, 29 de abril). Pandemia: maestros, tecnología y desigualdad. Nexos. https://educacion.nexos.com.mx/?p=2286

Roger, C. (1964). El proceso de convertirse en persona. Paidós.

SEP (2020, 15 de mayo). Pese a contingencia por Covid-19, 80\% de maestros y estudiantes se mantienen comunicados: SEP.

https://www.eluniversal.com.mx/nacion/coronavirus-pese-contingencia-80-demaestros-y-estudiantes-se-mantienen-comunicados-sep

UNESCO (2020, 21 de abril) Surgen alarmantes brechas digitales en el aprendizaje a distancia. https://es.unesco.org/news/surgen-alarmantes-brechas-digitalesaprendizaje-distancia

UNICEF (2020). Educación en tiempos de COVID-19. Juega y aprende con tus hijos e hijas en tiempos de COVID-19. https://www.unicef.org/mexico/educaci\%C3\%B3n-entiempos-de-covid-19

Viñals, A. y Cuenca, J. (2016). El rol del docente en la era digital. Revista Interuniversitaria $\begin{array}{lllll}\text { de Formación del Profesorado } 30 & \text { (2), } & \text { 103-114. }\end{array}$ https://www.redalyc.org/pdf/274/27447325008.pdf

Investigación e Innovación en Matemática Educativa (2020) Volumen 5 